\title{
A física do século XX
}

\section{Silvio R. A. Salinas}

M ICHEL PATY, pesquisador emérito do CNRS, fundador da "Equipe REHSEIS", grupo de trabalho sobre epistemologia e história das ciências da Universidade de Paris VII, que tem acolhido um bom número de estudantes brasileiros, foi pesquisador em "física das partículas elementares" no início de carreira, com posição de trabalho no Centro de Pesquisas Nucleares de Estrasburgo, transformando-se mais tarde em filósofo e historiador da ciência reconhecido, com diversos textos publicados na França e alguns no Brasil. Michel Paty está especialmente aparelhado para escrever sobre a física do século XX, que ele vivenciou como aprendiz e como pesquisador atuante, e que tem sido tema das suas reflexões de filósofo. É ótimo que um texto dessa qualidade, numa linguagem correta, mas evitando tecnicalidades e o formalismo matemático da física contemporânea, seja publicado em português, oferecendo material histórico e epistemológico para um público amplo.

O texto de Paty se inicia com uma palavra de cautela, pois talvez ainda não haja distanciamento para apreciar o impacto das ideias e descobertas dos últimos cem anos. O que diria sobre os cem anos anteriores um historiador da ciência no início do século XX? Acho que certas conquistas da "física clássica", incluindo os desdobramentos da mecânica newtoniana, a física de Laplace e Fourier, a construção da termodinâmica e do eletromagnetismo na segunda metade do século XIX seriam devidamente reconhecidas. Mas teria sido realmente difícil prever novos desenvolvimentos. Lord Kelvin, personalidade maior da física britânica nessa época, utilizava medidas de temperatura das minas, analisadas com a sofisticação da equação do calor de Fourier, para estimar a idade da Terra, colocando em xeque os cálculos geológicos e a teoria da evolução. No final do século, foi descoberta a radioatividade, fonte imensa de energia, e, no "ano milagroso" de 1905, Einstein propôs no contexto da relatividade a relação famosa entre massa e energia, mudando o panorama dos cálculos sobre a idade da Terra e do sistema solar. Cem anos depois, creio que também nos encontramos diante de dúvidas e indagações, especialmente nos domínios da nova cosmologia astrofísica e das tentativas de unificação dos campos fundamentais, que podem mudar a nossa visão da natureza, embora haja conquistas bem estabelecidas, como a teoria da relatividade e a mecânica quântica, tão bem descritas nesse texto.

Os capítulos iniciais percorrem a trajetória conhecida da física no século XX: relatividade, mecânica quântica, átomos e estados da matéria, o interior do núcleo atômico, os campos fundamentais e suas forças. Ninguém mais duvida do "modelo atômico", que se transformou na própria realidade física contemporânea, pois os átomos atualmente podem ser "vistos" nos microscópios de força atômica, mas a situação era bem diferente no início do século, sob a influência dos energeticistas, quando ainda não se conheciam os resultados das experiências de Perrin sobre o movimento browniano. As seções sobre a "interpretação dos conceitos quânticos" são particularmente interessantes. Apesar do extraordinário 


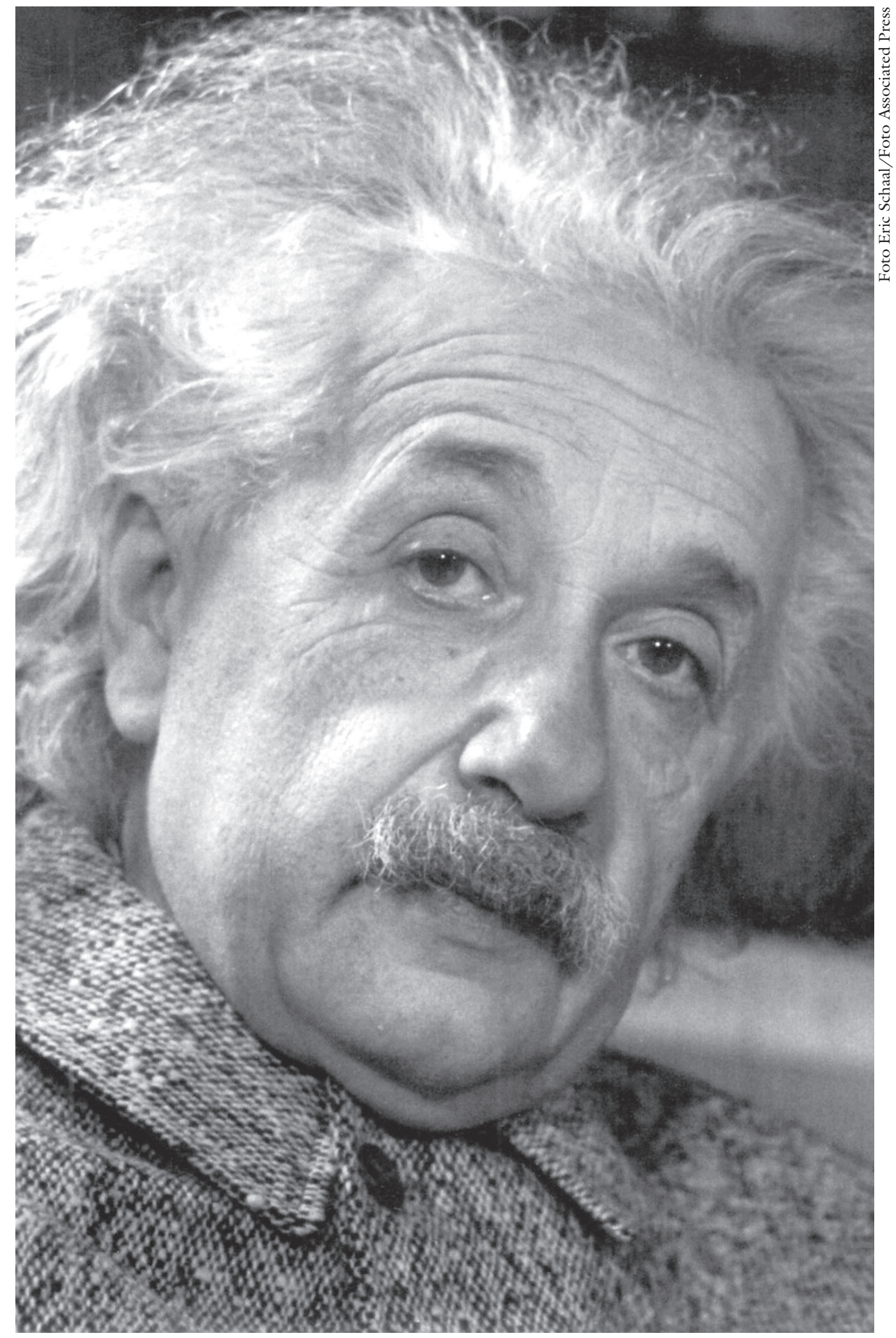

O físico e humanista alemão Albert Einstein (1879-1955). 
sucesso na explicação dos fenômenos na escala atômica, a mecânica quântica incorpora ideias de indeterminação e não localidade, que se chocam com a tradição determinista da física clássica. O problema da medida na mecânica quântica arrebatou opiniões durante parte do século XX: é difícil admitir que o "gato de Schroedinger" esteja numa combinação linear entre "a vida e a morte" antes que um observador (clássico) realize uma medida. Michel Paty relata o debate sobre os fundamentos da mecânica quântica, mostrando que certas questões acabaram sendo postas de forma mais objetiva, sendo finalmente submetidas ao teste da experimentação. As ideias de não localidade se traduziram nas desigualdades de John Bell, que finalmente foram testadas com lasers e equipamentos modernos da óptica física, revelando os "fenômenos de descoerência", compatíveis com a visão quântica. De certa forma, a dualidade onda-partícula, "problema epistemológico" da mecânica quântica, acabou se transformando na própria solução do problema! Segundo Paty, o princípio da superposição e a não comutação dos operadores quânticos tornaram-se aos poucos uma "segunda natureza", formando parte da nova "intuição física". Apesar dessa visão otimista, é preciso apontar certo incômodo que ainda permanece na física do século XXI. Será que a mecânica quântica fornece de fato a descrição definitiva da natureza? Ainda há dúvidas sobre fenômenos a distâncias muito curtas e sobre sistemas complexos, como o próprio gato de Schroedinger, que talvez não possa mesmo ser descrito quanticamente, além de especulações sobre a função de onda do universo, ou sobre a descrição quântica de um aglomerado de universos...

Os capítulos sobre a matéria subatô- mica - no interior do núcleo atômico, os campos fundamentais e as suas forças são particularmente primorosos, pois o autor se encontra à vontade, refletindo sobre seus antigos interesses e trabalhos de pesquisa. De forma breve, mas bem apropriada, vão sendo apresentadas as primeiras "partículas elementares", incluindo o méson identificado por Cesar Lattes e colaboradores nas emulsões fotográficas expostas no Monte Chacaltaya, na Bolívia, e posteriormente produzido “artificialmente" pelo próprio Lattes num dos primeiros aceleradores de partículas. A teoria das interações fracas, com neutrinos e antineutrinos, o predomínio dos campos, a unificação com o eletromagnetismo maxwelliano e a necessidade de "renormalização", a "multidão" de partículas elementares e de "ressonâncias" que vão sendo descobertas e resultaram no "modelo dos quarks" da década de 1960 são descritos com muita propriedade. Os quarks, partículas de carga fracionária com a propriedade de "confinamento", que não podem ser observadas no estado livre, explicariam a estrutura das partículas subnucleares. Esses resultados conduziram à proposta de um "modelo padrão" da física subnuclear, englobando as teorias eletrofracas e a "cromodinâmica" ou teoria de campos das interações fortes, com enorme dose de legitimidade, explicando até agora a miríade de fenômenos subnucleares, mas aguardando ainda certos testes experimentais, como a comprovação da existência de uma "supersimetria" misturando bósons e férmions, e a descoberta de uma partícula maciça, denominada "bóson de Higgs", que funcionaria como uma espécie de cola da matéria subnuclear. A ilustração da figura 7.4 é providencial para nos guiar pelas etapas dessa grande unificação, 
que se inicia com Maxwell unificando os campos elétricos e magnéticos, passa pela eletrodinâmica quântica, incorpora as interações fracas, inclui em seguida os campos fortes, mas deixa em suspenso o campo gravitacional, problema para ser resolvido pela física do século XXI. Michel Paty esteve no Brasil na década de 1960, como estagiário de cooperação do governo francês, participando das novidades e desventuras da Universidade de Brasília no início do período militar, e conheceu vários físicos que trabalharam no país. Registra o trabalho seminal de J. J. Giambiagi sobre "regularização dimensional", que contribuiu para lidar com os infinitos da eletrodinâmica quântica, mas não cita o coautor, Carlos Bollini, que também esteve entre nós, e faleceu muito recentemente na Argentina. Além disso, refere-se ao trabalho pioneiro de Leite Lopes, que foi um precursor da unificação da eletrodinâmica quântica com os campos das interações fracas.

No capítulo 5, “Átomos e estados da matéria", o tratamento dispensado à física do estado sólido, que engloba atualmente toda a matéria condensada, incluindo as aplicações de maior impacto da mecânica quântica, é infelizmente bem superficial. Afinal de contas, dificilmente estaríamos aqui escrevendo num laptop ou nos comunicando pela internet sem essa maravilha dos semicondutores, explicados pela teoria quântica das bandas eletrônicas de energia. A supercondutividade, em baixas e altas temperaturas, a superfluidez, a análise das propriedades elétricas e magnéticas dos materiais, o projeto de novos materiais, são conquistas do século XX. O americano John Bardeen ganhou o Prêmio Nobel duas vezes: pela descoberta do transistor, logo depois da guerra, e mais tarde pela proposta de uma teoria para a explicação da supercondutividade, com repercussões na própria formulação das teorias de campos.

Algumas escolhas de Michel Paty refletem preferências pessoais, opiniões do autor, que poderiam ser questionadas, mas que não prejudicam o conteúdo central. Por exemplo, acho difícil justificar longas seções sobre "sistemas dinâmicos", tema de maior repercussão no domínio da matemática, mas que se beneficiou enormemente da física computacional, que praticamente não é mencionada no texto. As conexões entre o caos determinístico e os fundamentos da mecânica estatística ainda precisam ser estabelecidas. Quase nada se fala sobre a própria mecânica estatística, em boa parte construída no século XX, com aplicações crescentes no domínio das "organizações complexas da matéria", ou na "física do cotidiano", forma pouco adequada de se referir aos interesses pioneiros de Pierre-Gilles de Gennes. $\mathrm{O}$ estudo das transições de fase e dos fenômenos críticos recebe tratamento superficial e às vezes equivocado, embora se mencione o "grupo de renormalização", técnica fecunda destinada a lidar com fenômenos sem uma escala bem definida, como as flutuações de tamanho das gotículas de um fluido nas vizinhanças do ponto crítico. Nesse caso, os materiais da física dos sólidos - e os modelos da física estatística - proporcionaram os testes adequados da teoria, que de outra forma teria que aguardar experiências delicadas (e caríssimas) no domínio das altas energias. Outras escolhas de Paty são interessantes, mas também me parecem um tanto distantes das conquistas do que se poderia delimitar como a física do século XX; refiro-me aqui ao capítulo 9, sobre a dinâmica da terra, com um apanhado dos avanços da geofísica, mencionando 
até as hipóteses sobre a extinção dos dinossauros, e ao capítulo 12, sobre as origens, com atenção especial às origens do homem, da vida e da terra, que sem dúvida podem ser atualmente analisadas sob um prisma cientificamente mais rigoroso, embora não haja um balanço da contribuição crescente dos físicos, pelo menos da aplicação aos sistemas biológicos de métodos e técnicas oriundos da física. Francis Crick, físico de formação, participou de uma das descobertas biológicas mais marcantes do século XX, utilizando técnicas de raios $\mathrm{X}$, e tendo sido estimulado talvez por conferências famosas de Schroedinger, indagando sobre a vida e sobre a mente.

Nos capítulos finais, sobre os objetos do cosmo (planetas, estrelas, galáxias, radiações) e sobre a cosmologia contemporânea (expansão e transformação do universo), Michel Paty retorna ao domínio histórico da física, que agora dispõe de uma imensa coleção de dados experimentais proporcionados por telescópios cada vez mais potentes, instalados até mesmo em estações orbitais. A astronomia contemporânea se associa à astrofísica e à cosmologia, permitindo indagações que no passado estariam fora dos domínios da ciência. A observação da radiação de fundo por Penzias e Wilson em 1965 suscitou o enorme impulso da cosmologia e dos seus modelos dinâmicos. A teoria geral da relatividade, aplicada inicialmente para explicar os avanços no periélio de Mercúrio e a curvatura dos raios de luz nas vizinhanças do Sol, pode agora ser aplicada para dar conta de fenômenos associados a sistemas maciços e compactos (pulsares, quasares e até buracos negros), com vantagens evidentes sobre a gravitação newtoniana. A procura por planetas fora do sistema solar se iniciou na últi-

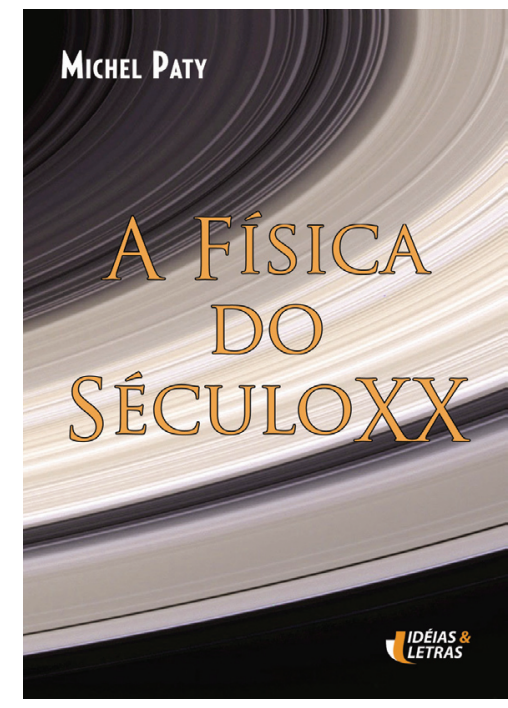

PATY, Michel. A física do século XX. Trad. sob coord. Pablo R. Mariconda. São Paulo: Ideias e Letras, 2009. 496p.

ma década e continua com vigor, antevendo no século XXI as pesquisas sobre outras formas de vida e de inteligência. Um resultado notável foi a detecção em 1987 de neutrinos em laboratórios do Japão e dos Estados Unidos em coincidência com a observação de uma estrela supernova na Nuvem de Magalhães. Talvez Paty pudesse ter mencionado o trabalho especulativo de George Gamow e Mario Schoenberg, na década de 1940, propondo o "processo Urca", em que os neutrinos transportam a enorme energia liberada pela formação da supernova, à semelhança das fortunas que trocavam de mão no cassino do Rio.

Paty argumenta que a cosmologia contemporânea é transformada em ciência física, sem restrições, a partir do estabelecimento empírico da lei de Hubble, propondo um universo em expansão constante. Como a distância fornece uma medida direta do tempo que a luz demora para chegar até nós, os hipertelescópios 
modernos permitem a investigação do universo nos seus primeiros estados, proporcionando contato com as observações nos grandes aceleradores, que consideram dimensões "infinitamente pequenas". Surge então o modelo teórico do "Big Bang", elevado ao status de "modelo padrão", embora haja dúvidas e problemas para o século XXI. Um balanço da massa do universo revela déficit impressionante, que seria preenchido pela "matéria escura”, praticamente não interagente com a matéria hadrônica normal. Medidas mais recentes indicam que a expansão do universo está sendo acelerada, fenômeno que se explicaria pela presença de energia escura, que também desconhecemos. Fala-se ainda no déficit do balanço de entropia. Em suma, há uma boa coleção de problemas para os físicos do século XXI, que talvez consigam quantizar o campo gravitacional e completar as atuais teorias de cordas...

Num dos últimos capítulos, sobre "objetos e métodos", Paty aborda a questão da "big science": a investigação do infinitamente grande exige hipertelescópios, situados às vezes em órbita espacial; a investigação do infinitamente pequeno, das curtíssimas distâncias, exige superaceleradores de partículas, com energias cada vez maiores, e certamente cada vez mais dispendiosos. Paty se refere ao CERN, consórcio de vários países europeus para colaboração na área de partículas elementares, que tenta colocar em funcionamento o maior desses aceleradores, $\mathrm{O}$ "Large Hadron Collider", ou LHC, um túnel com $27 \mathrm{~km}$ de circunferência, entre a França e a Suíça, e que talvez traga informações adicionais sobre a validade do “modelo padrão". Mas Paty não menciona o grande projeto da segunda metade do século XX, o "Superconducting Super
Collider", SSC, um anel com cerca de 90 $\mathrm{km}$, cuja construção chegou a ser iniciada no Texas, mas que foi descartado em 1993, quando o Senado americano vetou um orçamento que atingia uma dezena de bilhões de dólares. A "big science", praticada por equipes imensas, às vezes com centenas de pesquisadores, envolve instrumentos cada vez mais caros, talvez exorbitantemente caros, que dificilmente serão justificados pelos seus benefícios indiretos. Desde o Renascimento, passando pelas propostas do século XX, a física sempre se desenvolveu por meio do diálogo entre teoria e experiência, mas esse diálogo será mais complicado no século XXI.

Há poucos reparos ao texto: pequenos errinhos que podem ser corrigidos na próxima edição. Sugiro atenção à grafia de algumas letras gregas e de certos símbolos matemáticos. Os "quadros explicativos" e as ilustrações em geral são muito úteis. A tradução, com poucos deslizes, sob a responsabilidade do professor Pablo Mariconda, foi feita por um grupo de pesquisadores*, como o próprio coordenador esclarece em nota publicada em Scientia Studia. No final, há vasta bibliografia, além de índices de assuntos e nomes citados. Em suma, trata-se de ótimo texto em português, escrito para um público amplo, cumprindo com certeza a missão de transmitir ao leitor a "paixão intelectual" dessa aventura que foi a construção da física no século XX.

Silvio R. A. Salinas é professor do Instituto de Física da USP. @ - ssalinas@if.usp.br

* Irinéa de Lourdes Batista, Claudemir Roque Tossato, Maurício de Carvalho Ramos, Lúcio Campos Costa, Maria Aparecida Correa Paty e Olival Freire. 